\title{
On the Inheritance and Development of Tujia Maogusi
}

\author{
Chen Lu \\ College of International Education \\ Jishou University \\ Jishou, 416000, China
}

\begin{abstract}
Maogusi is a national intangible cultural heritage, an important basis for Tujia people to become a single nation, and the essence of Tujia culture. Under the impact of modern lifestyle, Maogusi is risk losing its name if not inherited and protected. This study has great theoretical and practical significance for digging out and sorting out traditional national sports and preserving and developing Maogusi. This paper investigates and analyzes the forms and characteristics of Tujia Maogusi by means of literature, field observation, expert interview and so on. It also puts forward some strategies for Tujia Maogusi to inherit by relying on Tujia language and heirs. At the same time, this paper puts forward that the protection function of the government should be increased, together with building Maogusi national culture industry with the help of tourism, incorporating physical education teaching in schools, increasing capital input, expanding education publicity, innovating the movement elements of Maogusi by integrating folk dance or aerobics. Thus, it provides certain theoretical reference for better inheriting national culture and promoting national intangible cultural heritage of Tujia Maogusi.
\end{abstract}

\section{Keywords-Maogusi; inheritance; development}

\section{INTRODUCTION}

The Intangible cultural heritage and material cultural heritage together constitute the cultural wealth of the Chinese nation and are an important part of the cultural heritage of all mankind, making outstanding contributions to the progress and development of human civilization. Therefore, strengthening the inheritance and protection of China's intangible cultural heritage is not only the development needs of the whole country, but also the needs of the cultural diversity of the world, which is an inevitable requirement to maintain the sustainable development of the world and human society.

World intangible cultural heritage-Maogusi is a traditional sport of Tujia nationality with a long history, which is mainly spread in Yongshun, Longshan, Baojing, Guzhang and other Tujia settlements and surrounding areas in Xiangxi Tujia and Miao Autonomous Prefecture of Hunan province. It is a traditional sport with characters, dialogues, plots and certain forms of performance. The dancers wear thatched grass during the performance, and the images are primitive. Maogusi is rich in content, including primitive fishing and hunting, agricultural production, family bonding, reading, etc., which contains a wide range of cultural values such as art, culture, religion, folk custom, history, etc., and is an important part of the protection of Tujia traditional culture with profound accumulation.

\section{THE CONTENT AND CHARACTERISTICS OF THE PERFORMANCE OF TUJIA MAOGUS}

The performances of Maogusi mainly reflect the production and life of ancient Tujia ancestors, such as sweeping the temple, offering sacrifices to the gods, hunting, digging, fishing, etc. The performer shook his whole body, making the rustle of his straw clothes, walking with drunken steps, swinging from side to side, shaking his head. In addition, they imitate the primitive and rough movements of ancient people, speak Tujia language, sing Tujia songs, and integrate songs, dances and words into one.

The movements of Maogusi are characteristic. A performer's knees are bent, his whole body shaking and rustling, and his five braids swinging from side to side. $\mathrm{He}$ shuffles in and out, swings from left to right and shakes his head and shoulders. According to the action of the performance, the contents can be clear at a glance, such as dew beating, sweeping in and out, hunting, hunting to celebrate victory and so on.

\section{THE INHERITANCE STRATEGIES OF TUJIA MAOGUSI}

In the development trend of economic globalization and modernization in the 21 st century, the economy and education of minority areas have been gradually developed. Many children over there have gone on to higher education or work in economically developed coastal cities to change their way of life, so there are fewer young people performing Maogusi. Maogusi has been facing the crisis of disappearance or loss, so it is imperative to rescue and protect Maogusi intangible cultural heritage. In this paper, the author puts forward the inheritance strategies of Maogusi from its own characteristics and problems in its development.

\section{A. Inheritance by Tujia language}

A very important feature of Maogusi is that the narration of the performance is in Tujia language. During a Maogusi performance, a performer speaks Tujia language and sings Tujia songs from beginning to end. Tujia has language but no writing, so everyone is in the form of oral transmission. Now many children can't understand the Tujia language, and 
Maogusi, whose language carrier is Tujia, is even more lost. In order to develop Maogusi, we must rely on modern science and technology, advanced electronic technology and photographic equipment to record Tujia language from those living Tujia elders. In the preservation of Maogusi language, we can first record the pronunciation of dialogue by Tujia old people in Maogusi with electronic equipment, and then compile Maogusi dialogue in the form of spelling or Chinese characters. In this way, the old language will not be lost with the death of the old man. Relevant governments can establish a linkage and coordination mechanism for the protection of Tujia cultural heritage in the Tujia settlements, so as to confirm, document, study and inherit the language in the narration of Maogusi. In schools in ethnic minority areas where conditions permit, Tujia language learning can be introduced into classroom learning in primary and secondary schools, so as to educate local residents in Tujia language since childhood.

\section{B. Inheritance by heirs}

The key to protecting Maogusi is the heirs, especially those familiar with Maogusi culture. Now that there are fewer and fewer old Maogusi artists left in the world, the local government should make relevant policies to encourage the old Maogusi artists to pass on their skills and encourage local young people to learn Maogusi. This way in which the old artists train their heirs, can maintain the original ecology of Maogusi. The government should adjust the structure of local economic development to combine the economic development with the protection of intangible cultural heritage organically. We should establish a people-oriented, scientific and effective inheritance mechanism and encourage the inheritors of Maogusi to carry out the inheritance activities in a variety of ways. In the end, the purpose is to make the young people who stay in the area benefit from the protection of intangible cultural heritage, so that the young local artists can participate in the succession.

\section{The DEVElopment StRATEgIES OF TUJIA MAOGUSI}

China is a society in which many ethnic groups coexist and the development of traditional ethnic sports is limited by geographical and cultural environment. Most of the traditional ethnic sports retain more of the original features of the early period, and some are closely integrated with local folk activities, production and life. Maogusi is an ancient national sport with strong teaching skills. The descendants of the Tujia ethnic group evolved Maogusi as a kind of sport by imitating the hunting and fishing techniques and farming techniques in daily life.

\section{A. Stepping up Government Efforts to Protect Maogusi Intangible Cultural Heritage}

The Chinese government comprehensively promotes the protection of intangible cultural heritage and takes the protection and development of excellent intangible cultural heritage as an important part of the development of China's cultural industry. The management system should be straighten out and the coordination mechanisms should be established between localities and departments so as to work together. Governments at all levels should also bring the Maogusi rescue project into the economic and social development plan, provide practical support in human, material and financial resources, increase financial input, and establish a sound Maogusi protection and investment mechanism. The local government should make use of modern scientific and technological means such as audio recording, video recording and digital multimedia to record Maogusi in a real, systematic and comprehensive way and establish archives and databases. Folk culture villages should be set up in Tujia settlement areas, and Maogusi protection zone should be selected to be listed for protection in the name of the government. On this basis, the system of government subsidies for inheritors of folk art should be gradually established and improved. A number of inheritors of folk art should be appointed every year and enjoy the government subsidies paid regularly. The government can also carry out regular repairs to the existing hand-waving exhibition hall, protect old folk artists in Maogusi, and build Maogusi cultural and ecological museum.

\section{B. Building Maogusi Ethnic Culture Industry with the Help of Tourism}

With the help of abundant tourism resources, various kinds of sports activities with local customs and ethnic characteristics can be carried out in Maogusi tourist area. And it is also extremely important to integrate Maogusi with local tourist attractions, offer Maogusi as a featured program for tourists, and make them participate in the performance of Maogusi as much as possible. In this way, tourists can not only feel the beauty of mountains and rivers, but also appreciate the local ethnic customs with strong characteristics, feel the Tujia ethnic sports culture and experience the charm of Maogusi, so as to realize the complementary advantages of ethnic culture and natural resources. In this way, we will not only develop Maogusi, but also promote the local economy, tourism and culture, thus achieve the goal of common development. At present, some minority Tujia areas have put Maogusi on the stage, such as the charming Xiangxi theater in Wulingyuan scenic area of Zhangjiajie and the large bonfire night in Fenghuang ancient city, etc, from which we can see that Maogusi performances are popular with tourists. In addition, Maogusi also boarded the 7th Beijing international tourism and culture festival opening ceremony and dressingdown performance. In these processes, the industrial operation of Maogusi can obtain high returns and promote the excellent Tujia culture.

\section{Incorporating Maogusi into Physical Education in School}

Local colleges and universities should shoulder the historical responsibility of protecting intangible cultural heritage. The local government should encourage the middle and high-end talents of institutions of higher learning and scientific research institutions to carry out scientific research combining theory with practice, turn scientific research results into knowledge system, form scientific theories, and then use scientific theories to guide practical work, and train Maogusi successors in institutions of higher learning and scientific research institutions. We can also refine and edit Maogusi fitness teaching textbooks and create more dance works by changing and developing them. We should cultivate their sense of national identity and enhance their sense of responsibility to protect and promote their national traditional sports, so as to become potential successors of Maogusi. 


\section{Expanding Education and Publicity}

Maogusi is a national intangible cultural heritage. It is impossible to determine the specific time when Maogusi took shape because there is no written record. However, it can be confirmed that Maogusi has existed for thousands of years through archaeological research. Due to the local geographical restrictions, Maogusi has been spread only in Yongshun, Longshan, Guzhang and other Tujia areas, so few people outside the world know or understand him. With the progress of modern society and the development of the traffic roads and the transportation means, there are more and more exchanges between the outside world and the autonomous prefecture, so that people have the opportunity to have a deeper understanding of local folk customs, and to appreciate the charm of traditional local ethnic sports. Newspapers, radio, television and other mass media can also be used to promote Maogusi. And Maogusi can also be performed in our national minority traditional sports games. Through the promotion of national traditional sports games, Maogusi not only can promote the development of all kinds of traditional ethnic sports, enhance the friendship and mutual cooperation spirit of solidarity between the ethnic, strengthen ethnic's health, but also can promote learning from each other, create a more rich and colorful spiritual culture construction of the Chinese nation. Modern network tools can be used to upload the live recorded performance of Maogusi video to the network, so that more people can know it and the awareness of Maogusi can be improved.

\section{E. Innovating the Movement Elements of Maogusi and Incorporating Folk Dance or Aerobics}

The innovation of Maogusi is to enhance its appreciation and entertainment on the basis of retaining national characteristics. Artistic innovation is a necessary condition for the development of each national traditional sports. Previous performances were single, rigid and lack of individuality. Maogusi learned from the successful innovation experience of Tongling dance and organized experts to innovate the choreography and music creation, adding the elements of the age, so that it not only meets modern people's aesthetic standards, but also retains the original artistic quality. To do a good job in the innovation of Maogusi art, we should first maintain its local characteristics in our work, and at the same time make it adapt to the requirements of the age. The Maogusi dance, which is permeated with the living state, lifestyle and life belief of Tujia people, is funny in performance. The shaking of each part of the performers' body is the main moving law. The walking steps are broken, the knees are shaken, the left and the right parts are swinging, and the whole body trembles. At the same time, it can also be created into a simple and distinctive national aerobics, whose high fitness value and appreciation can be loved by fitness enthusiasts.

\section{CONCLUSION}

Maogusi is a national intangible cultural heritage whose inheritance, protection and development cannot be separated from the support of the government. There are many things the government can do, such as formulating relevant regulations to strengthen the protection of Maogusi intangible cultural heritage, increasing capital input and correctly channeling capital into the protection of Mao gusi, increasing external publicity efforts to promote the development of Maogusi, and paying attention to the technical movement and the propaganda of the cultural connotation of Maogusi. The development of Maogusi can use the modern developed electronic information, advanced network media technology, field performance, written tourism album and other publicity methods, to show the characteristics of traditional national sports charm to the world.

\section{REFERENCES}

[1] Bai Jinxiang. A study on the Social Construction of the Protection of Traditional Sports Intangible Cultural Heritage in Minority Communities -- a Case Study of the Miao Nationality's Lion Snatching Custom in Daxing Village in Western Hunan Province[J]. Sports Science, 2012(8).

[2] Bai Jinxiang. The Protection of Intangible Cultural Heritage and Traditional Sports Culture in China[J]. Sports Science, 2008(01).

[3] Liu Jian. Research on the Protection and Inheritance of Traditional Sports Intangible Cultural Heritage of Ethnic Minorities in Yunnan Province [D]. Beijing Sport University 2012

[4] Zhang Wei. The Primitive Worship Consciousness and Aesthetic Implication of Tujia Maogusi Dance[J]. Sichuan Sports Science, 2011(1)

[5] Chen Yanliang and Yao Saihong. The Cultural Origin of Tujia Maogusi and the Protection of Intangible Cultural Heritage[J]. Folk Culture Forum, 2005 (6): 80.

[6] Zhuo Nini. Preliminary Exploration on the Re-creation of Maogus Dance in Xiangxi[J]. The Research Institute of Xiangxi Autonomous Prefecture National Literature and Art Creation, 2009(4) :45. 